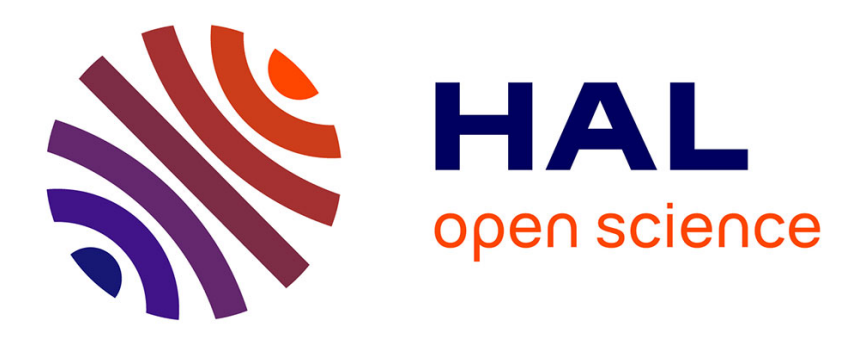

\title{
Ordering phenomena during the structural relaxation of sputtered Ni 24Zr76
}

\author{
E. Balanzat
}

\section{To cite this version:}

E. Balanzat. Ordering phenomena during the structural relaxation of sputtered Ni 24Zr76. Journal de Physique Lettres, 1984, 45 (12), pp.639-646. 10.1051/jphyslet:019840045012063900 . jpa-00232392

\section{HAL Id: jpa-00232392 https://hal.science/jpa-00232392}

Submitted on 1 Jan 1984

HAL is a multi-disciplinary open access archive for the deposit and dissemination of scientific research documents, whether they are published or not. The documents may come from teaching and research institutions in France or abroad, or from public or private research centers.
L'archive ouverte pluridisciplinaire HAL, est destinée au dépôt et à la diffusion de documents scientifiques de niveau recherche, publiés ou non, émanant des établissements d'enseignement et de recherche français ou étrangers, des laboratoires publics ou privés. 
Classification

Physics Abstracts

$61.40-62.40$

\title{
Ordering phenomena during the structural relaxation of sputtered $\mathrm{Ni}_{24} \mathbf{Z r}_{76}$
}

\author{
E. Balanzat \\ Centre d'Etudes Nucléaires de Grenoble, Département de Recherche Fondamentale, \\ Section de Physique du Solide, 85 X, 38041 Grenoble Cedex, France
}

(Reçu le 27 mai 1983, révisé le 22 mars 1984, accepté le 19 avril 1984)

\begin{abstract}
Résumé. - L'évolution structurale d'un alliage amorphe, $\mathrm{Ni}_{24} \mathrm{Zr}_{76}$, obtenu par pulvérisation, a été étudiée dans l'ensemble du domaine de température situé au-dessous de la température de cristallisation. Ce travail comporte principalement des mesures de résistance électrique et de module de cisaillement. Pour rendre compte des variations observées au cours des différents traitements thermiques, deux processus distincts doivent être considérés. L'un d'eux donne lieu à un effet réversible.

Abstract. - The structural evolution of an amorphous metallic alloy of composition $\mathrm{Ni}_{24} \mathrm{Zr}_{76}$ produced by sputtering was studied at temperatures below the onset of crystallization by means of electrical resistance and shear modulus measurements. Analysis of the variations observed for these two physical parameters leads to the conclusion that two distinct processes are operative in the structural relaxation. One of them gives rise to reversible resistivity and modulus effects.
\end{abstract}

The evolution of the structural state of amorphous alloys during thermal treatments at temperatures where the degree of local order is increased, while no crystallization is detected, is generally termed structural relaxation. The detailed study of this process has rapidly developed in the last few years. In particular some physical properties have been shown to exhibit reversible variations during temperature cycles, which suggests the existence of a temperature dependent metastable equilibrium state. This effect is manifested at temperatures well below the glass transition temperature, $T_{\mathrm{g}}$. Under these conditions, the complete system cannot be in the metastable equilibrium state of the undercooled liquid, but it is rather a metastable state with respect to both the undercooled liquid and crystalline states. Consideration of a partial equilibrium which would imply local rearrangements involving a limited number of atomic jumps seems more appropriate. In fact, two interpretations have been put forward : (i) a local equilibrium of the type corresponding to the undercooled liquid takes place in some regions of the material only, i.e. those with atomic mobility higher than average [1,2]; (ii) several types of order exist and their respective evolutions can be distinguished $[3,5]$. In this respect, it is usual to refer to compositional short range order (CSRO) and topological short range order (TSRO) [5]. In principle, completion of equilibrium CSRO requires only a few elemental atom jumps, which explains the fact that the equilibrium state can be reached at temperatures well below $T_{\mathrm{g}}$. A recent study [6] has shown that, in this scheme also, the amorphous alloy must not be considered to be homogeneous. Instead, from detailed analysis of the observed ordering kinetics, the existence of geographical 
zones each characterized by specific atomic mobility and degree of compositional order can be inferred. It is hoped that this work will help separate and identify the different underlying processes which intervene in structural relaxation.

The $\mathrm{Ni}_{24} \mathrm{Zr}_{76}$ alloy which will be examined has already been widely studied from the view point of its formation and stability [7], crystallization [8], electronic properties [9], superconductivity $[10,11]$ and low temperature transport properties [12]. The present paper deals more precisely with shear modulus and electrical resistivity measurements conducted during heating and quenching cycles. In both studies, a reversible effect has clearly been distinguished from a non-reversible evolution. Comparison of the observed variations for the two physical parameters shows that different relaxation modes have to be invoked for both reversible and nonreversible parts.

\section{Experimental details.}

The amorphous $\mathrm{Ni}_{24} \mathrm{Zr}_{76}$ alloy was prepared by sputtering.

To avoid any possible room temperature relaxation, the alloy was stored in liquid nitrogen until utilization. X-ray and calorimetric analysis were done to check the amorphous state of the samples [22]. Samples were strips $0.4 \mathrm{~mm}$ wide, 1.3 to $2 \mathrm{~cm}$ long cut in the original $100 \mu \mathrm{m}$ thick sheet. For the modulus measurements, they were mounted in an inverted pendulum adapted to the use of thin strips and operated at frequencies of around one hertz.

The dynamic shear modulus, $\mu$, is related to the oscillation frequency, $f$, by

$$
\mu=\frac{I}{12 \pi} f^{2} \frac{L}{e^{3} \cdot l}
$$

where $I$ is the axial inertia momentum. $L, l$ and $e$ are the sample length, width and thickness, respectively. Assuming the dimensional changes to be isotropic yields

$$
\frac{\Delta \mu}{\mu}=2 \frac{\Delta f}{f}-\frac{\Delta v}{v}
$$

The relative volume changes, $\frac{\Delta v}{v}$, which are likely to occur during structural relaxation and crystallization are of the order of $1 \%$, which are small compared to the expected modulus changes of 20 to $30 \AA$ [13], Thus frequency variations predominantly arise from modulus changes.

The longitudinal load, $10^{-1} \mathrm{~N}$, was low enough to avoid creep. The measuring amplitude corresponded to a maximum strain of $10^{-4}$. It was verified that frequency did not depend on amplitude, in the range studied. Internal friction was determined simultaneously with frequency by measuring the logarithmic decrement of free oscillations, $\delta$.

The temperature cycle consisted of $10 \mathrm{~min}$ isochronal anneals conducted in situ, in a furnace with low thermal inertia. The anneal temperature was reached by heating at a constant rate of $150 \mathrm{~K} \mathrm{~min}^{-1}$ or $5 \mathrm{~K} \mathrm{~min}^{-1}$. In the latter case, modulus and internal friction could be determined directly during the temperature rise. After every anneal, the existing structural state was frozen in by the injection of helium gas precooled at $80 \mathrm{~K}$. Subsequently, measurements were made at the reference temperature of $310 \mathrm{~K}$.

The corresponding modifications of the electrical resistance produced by similar anneal and quench sequences were determined on a similar sample placed in a liquid helium cryostat and heat treated in a furnace surmounting the cryostat. All measurements were at $4.2 \mathrm{~K}$. More details are given in references [5] and [6]. 


\section{Results.}

Figure 1 illustrates the respective evolutions of the electrical resistance and the shear modulus which take place during back and forth temperature cycles and post-quench anneal sequences. The samples had first been stabilized for $30 \mathrm{~min}$ at $500 \mathrm{~K}$. Then, the experimental procedure was as follows. Isochronal anneals were made at successively decreased and increased temperatures. It is seen in figure la that, in the range of high temperatures, the resistance data points are located on two close, temperature dependent curves. From previous work [6], it follows that, to a first approximation, the system follows the equilibrium state characteristic of each temperature. At lower temperatures, the atomic mobility is too low to enable the state of order to evolve further, so that the data points tend to get aligned on a plateau. A different procedure is one in which, after the initial quench from the stabilization temperature, the sample is given isochronal anneals, starting from $300 \mathrm{~K}$. This treatment results in the progressive elimination of the frozen-in disordered state. This gives rise to an ordering stage, until the equilibrium line is reached again at higher temperatures.

Figure $1 \mathrm{~b}$ shows that the general features of the variations of both the shear modulus and resistance with temperature are identical. In particular the ordering stage and the knee in the back and forth annealing sequence occur at comparable temperatures. However a slight upward shift is detected during successive anneal sequences, which denotes less efficient stabilization than for the resistance experiments.

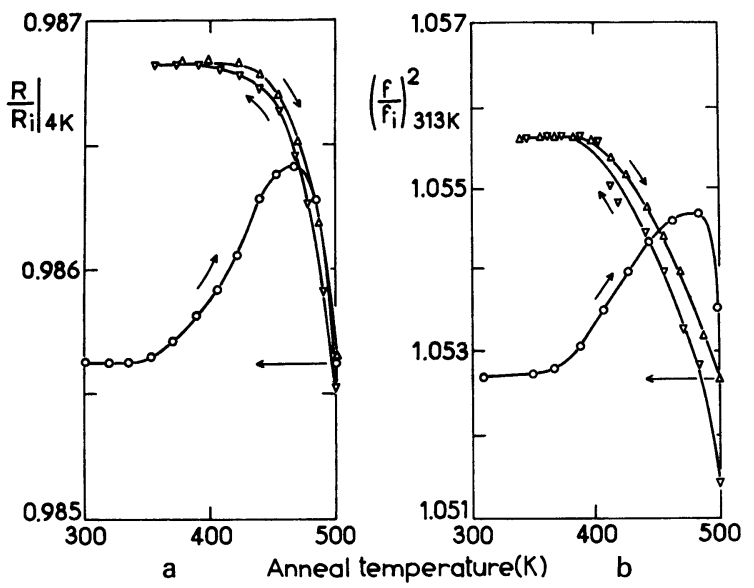

Fig. 1a. - Resistance variations vs. anneal temperature, in a prestabilized $\mathrm{Ni}_{24} \mathrm{Zr}_{76}$ sample. All measurements were at $4 \mathrm{~K}$. They were referred to the initial value for the as-sputtered condition.

Fig. 1 b. - Shear modulus $v$ s. anneal temperature, in a prestabilized $\mathrm{Ni}_{24} \mathrm{Zr}_{76}$ sample. All measurements were at $310 \mathrm{~K}$. They were referred to the initial value for the as-sputtered condition.

Interestingly the reversible modulus effect presented in figure $1 \mathrm{~b}$ can also be evidenced during measurements at the anneal temperature. To demonstrate this, the same specimen was given two different treatments. First a stabilization treatment at $500 \mathrm{~K}$ followed by a quench. Clearly the subsequent state reflects the state of order characteristic of $500 \mathrm{~K}$. Second, after standardization at $500 \mathrm{~K}$, the sample was slowly cooled (at a rate of $0.5 \mathrm{~K} \mathrm{~min}^{-1}$ ) down to $400 \mathrm{~K}$ and annealed for 10 hours at this temperature. This treatment resulted in an increased degree of order, the one for $400 \mathrm{~K}$. As a consequence, during further heating (curve 2 in Fig. 2) only disordering can occur. Accordingly it is expected that an additional modulus decrease will be super- 


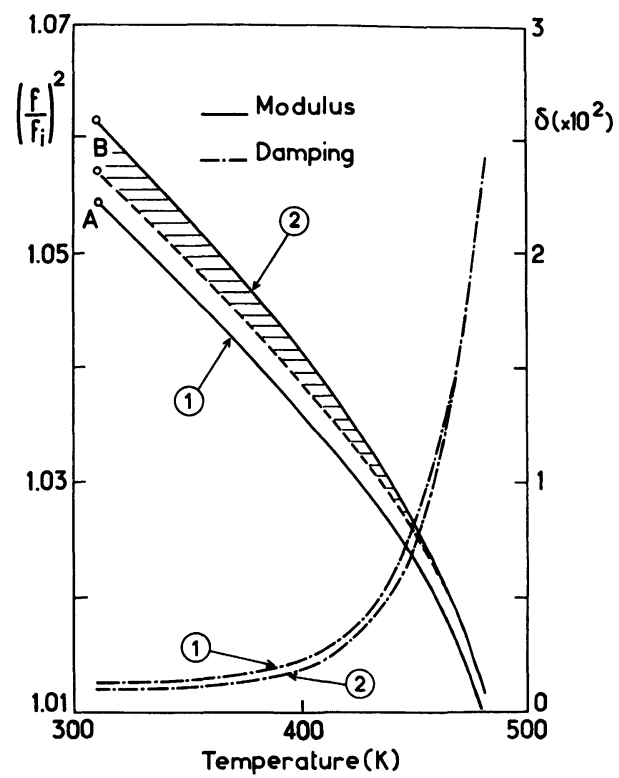

Fig. 2. - Modulus (full curves) and internal friction (dashed curves) vs. anneal temperature measured in a specimen heated at $0.5 \mathrm{~K} \mathrm{~min}^{-1}$ after equilibration treatment at $500 \mathrm{~K}$ (curve 1) or $400 \mathrm{~K}$ (curve 2) followed by a quench. After the final heating up to $500 \mathrm{~K}$, the sample was quenched again from this temperature, which should have restored the initial modulus value (point $A$ ). In reality, a slight non-reversible effect was detected, indicated by the shift from A to B. The hatched area is to show the approximate modulus increase associated with short range ordering. For the sake of comparison, curves 1 and 2 were brought into coincidence in their high temperature (equilibrium) portion. $\delta$ is the logarithmic decrement of the free oscillations.

imposed on the modulus decrease that normally occurs when the temperature is increased. In contrast, heating after the former treatment (curve 1 in Fig. 2) should result initially in ordering. Thus the modulus should increase, until thermally induced disordering prevails again. This was verified by the experiment, as indicated by the hatched area in the figure. It is noted also that the internal friction is not markedly influenced although a slight difference exists in the background damping. Whether this difference originates in the differing SRO states or is linked to the non-reversible shift is not clear.

Figure 3 shows the evolution pattern for both electrical resistance and elastic modulus during the first isochronal heat up sequence conducted on the as-received material. Above about $350 \mathrm{~K}$, the electrical resistance starts decreasing, while the modulus increases. The two effects are of a different magnitude from the reversible variations measured after stabilization. Figure 4 illustrates the influence of the structural relaxation which occurs during the above sequence on the thermal variations of the shear modulus and internal friction. The relaxation induces a strong increase of the shear modulus, but it has no marked effect on its temperature coefficient. The damping increases with temperature in a manner widely observed in glassy metals [13]; in particular, above a given temperature, the internal friction becomes strongly temperature dependent. This effect arises from the advent of viscoplastic processes [14]. It is progressively delayed towards higher temperature as structural relaxation proceeds.

\section{Discussion.}

The sensitivity of the modulus (or the resistivity) in metallic glasses to the degree of order is not known at the moment. Thus no quantitative information about the amount of ordering 


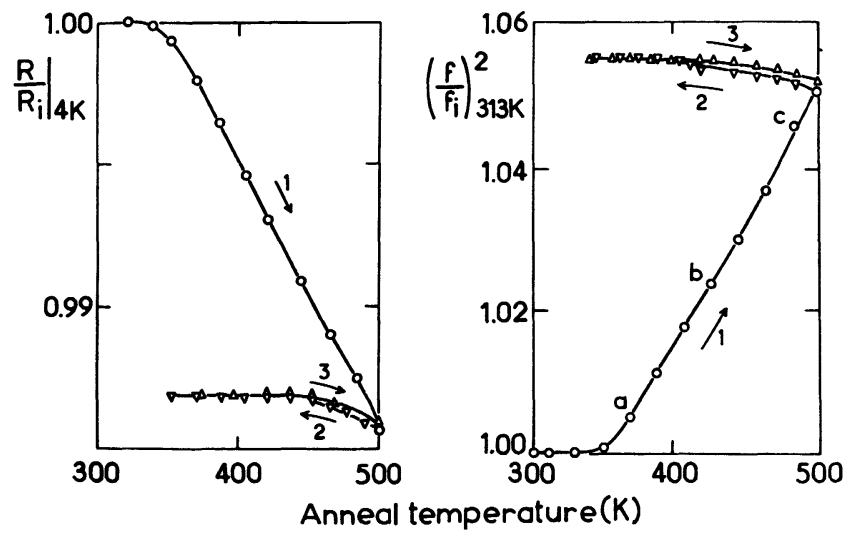

Fig. 3. - Resistance and modulus changes as a function of anneal temperature. The samples studied were originally in the as-sputtered condition. All treatments were $10 \mathrm{~min}$ isochronal anneals. The arrows show the successive anneal sequences. a, b and $c$ are to identify some of the curves in Fig. 4.

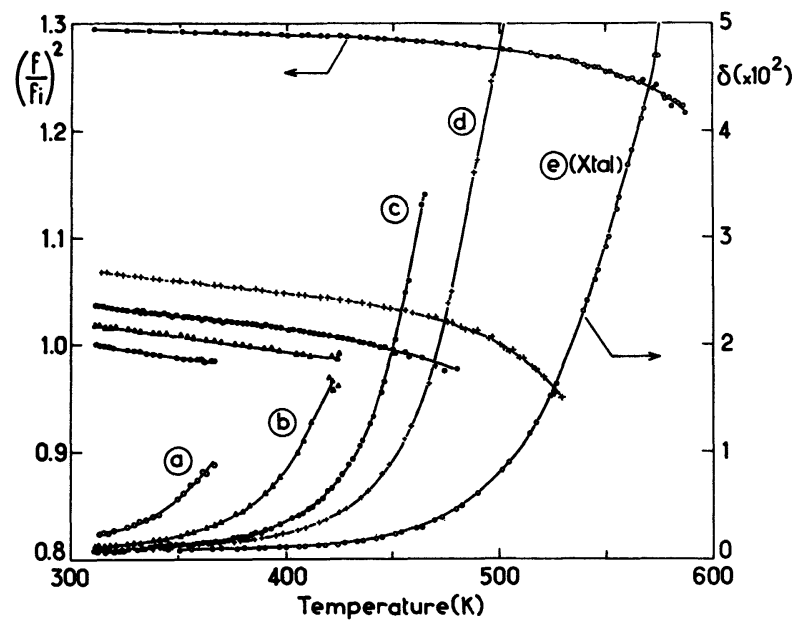

Fig. 4. - Influence of the structural relaxation on the variations of shear modulus and internal friction with temperature. All the curves correspond to heating at a constant rate of $5 \mathrm{~K} \mathrm{~min}^{-1}$ after the anneal sequence of Fig. 3 stopped at a, b or c, or after additional anneals at $500 \mathrm{~K}$ for two hours (d) or 20 min at $660 \mathrm{~K}$ (e : crystalline state).

associated with structural relaxation can be inferred from the magnitude of the observed modulus or resistivity variations. What is more, even the signs of evolution of these physical properties do not give any direct information about the structural processes involved. For comparison, it is recalled that in simple crystalline alloys, short range ordering can increase or decrease the resistivity, depending on the nature of the alloy constituents. Possibly, comparison of the results for the two parameters will shed some light on the processes which are operative during structural relaxation. In prestabilized samples, it can be first noted that the shape and location of the respective modulus and resistivity curves are very similar. This means that the corresponding kinetics are nearly identical and suggests that the same atomic reorganizations are involved. Interestingly, these influence the physical properties, considered above, in the same way. In 
contrast the respective evolutions of the two parameters which take place during the first heat up are of opposite sign. If a monote relation between the structural changes and resulting physical property variations is assumed, one is led to conclude that this reversal implies the existence of at least two distinct mechanisms.

On this basis, the observed changes can schematically be described with the help of two order parameters, $S_{1}$ and $S_{2}$, which can be considered to be roughly independent (Fig. 5). For simplicity, in the following, the $S_{1}$ variations are identified with the " reversible " effect, while those of $S_{2}$ are associated with the non-reversible effect. The relaxation of both $S_{1}$ and $S_{2}$ which occurs during the first heat up run reflects the annealing of the highly disordered state originally frozen-in during the quench from the melt. These initial states correspond to fictive temperatures $T_{\mathrm{f}_{1}}$ and $T_{\mathrm{f}_{2}}$. Obviously they cannot be reproduced during further treatments at subcrystallization temperatures. After a stabilization treatment at $T_{\mathrm{s}}$, the evolution which results from temperature cycles below $T_{\mathrm{s}}$ is essentially of reversible character and reflects the variations of $S_{1}$.

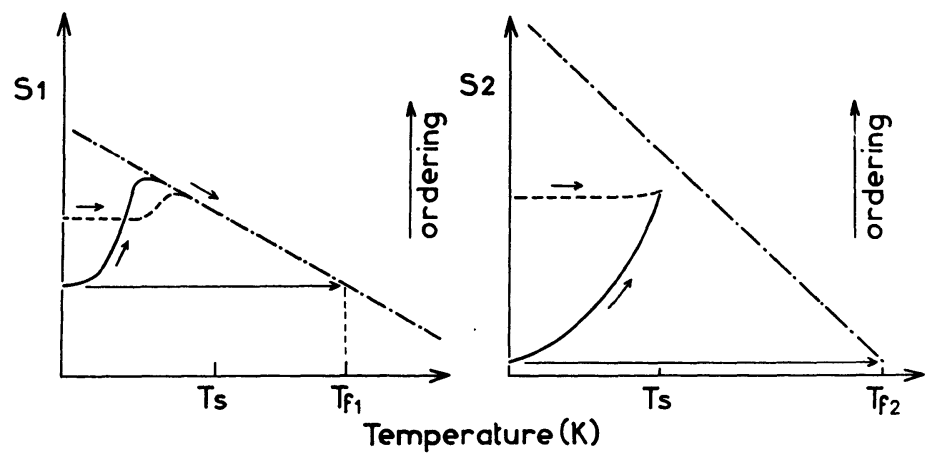

Fig. 5. - Schematic of the structural evolution in terms of the order parameters $S_{1}$ and $S_{2}$. (- - - Equilibrium state of order. (-) Evolution during the first heating to a stabilization temperature $T_{\mathrm{s}}$. The initial as-sputtered state corresponds to an equilibrium value at a fictive temperature $T_{\mathrm{f}_{1}}$ or $T_{\mathrm{f}_{2}}$ (--.--) Evolution during heating of a sample quenched from $T_{\mathrm{s}}$.

Taking into account the existence of the two processes, the next question is concerned with the problem of the respective sensitivities of modulus and electrical resistivity to each of these processes. Considering that resistivity is only sensitive to the reversible effect can be disregarded. If this were the case, since resistivity starts decreasing at temperatures close to ambient, the degree of order would continuously decrease which would imply a maximum temperature of $300 \mathrm{~K}$ for the freeze-in of the reversible order. This seems unrealistic. Thus, resistivity is sensitive to $S_{2}$ as well as to $S_{1}$. It is underlined that $S_{2}$ ordering leads to a resistance decrease (Fig. 3), while $S_{1}$ type ordering gives rise to resistance variations of opposite sign.

It is less clear whether the modulus is sensitive or not to $S_{2}$ ordering. If not, the modulus increase observed during the first heat up would simply be a reflection of the recovery of the initial $S_{1}$ frozen-in disorder. It is noted in figure 4 that annealing at $540 \mathrm{~K}$ results in a modulus increase of $6.8 \times 10^{-2}$ which, taking the experimental variation of $5 \times 10^{-5} \mathrm{~K}^{-1}$ for the temperature dependence of the " equilibrium " modulus implies that the frozen-in state of order corresponds to " equilibrium " at $1500 \mathrm{~K}$. Such a high degree of initial disorder is unlikely in amorphous alloys quenched from the melt. In these alloys the fictive temperature for freezing of the short range order is usually considered to be about 100 degrees above the glass temperature determined by heating $[1,15]$. However, in a sputtered material, no relevant experimental data is available. Nevertheless, we are inclined to think that both $S_{1}$ and $S_{2}$ ordering result in hardening. Scott et al. [4] were led to the same conclusion for a melt-quenched $\mathrm{Fe}_{40} \mathrm{Ni}_{40} \mathrm{~B}_{20}$ alloy. 
The identification of the physical nature of the reversible and non-reversible changes is still open to discussion. Elimination and/or redistribution of free volume are probably involved in the non-reversible effect. The possible existence of elastic inhomogeneities, such as the compressive and dilatation zones proposed by Egami (on the basis of an atomistic model [16]) together with their progressive elimination, has to be taken into account. The measured macroscopic shear modulus is undoubtedly influenced by these elastic inhomogeneities; it is recalled that, in irradiated crystalline metals, the modulus is markedly decreased by the existence of the elastic strain fields associated with self-interstitials [17].

A likely interpretation of the reversible changes can be in terms of compositional short range ordering. Indeed, the observed effects in metallic glasses are akin to the ones associated with chemical SRO in crystalline alloys $[18,19]$. In fact, variations in the degree of CSRO are expected to be more or less reversible. They require a few elementary atom jumps only, which explains why they can be observed in non-equilibrium phases. An interesting comparison can be made with the crystalline $\mathrm{Au}_{70} \mathrm{Ni}_{30} \alpha$-solid solution. A recent study has shown that SRO could be analysed at temperatures well below the miscibility gap, that is in metastable conditions, without any disturbing influence of non-reversible unmixing [20].

A reversible effect has already been evidenced in several metallic glasses, by using electrical resistivity, elastic modulus, Curie temperature and calorimetric measurements [21]. However, all these results have dealt with materials quenched from the liquid. To our knowledge, the present work is the first evidence of a reversible effect in glasses produced by sputtering. Using resistometric methods, we have made a comparative study of $\mathrm{Ni}_{24} \mathrm{Zr}_{76}$ samples prepared by the two processes, sputtering and melt spinning. The salient feature is that identical reversible effects are observed for the two types of preparations. Detailed results will be published elsewhere.

The existence of a reversible modulus effect in $\mathrm{Ni}_{24} \mathrm{Zr}_{76}$ also aids in the interpretation of the reversible variations of the superconducting temperature which were found by Anderson et al. [11] in melt-quenched $\mathrm{NiZr}$ of same composition. These authors have invoked the existence of a modulus effect to explain their results. On account of the present modulus results and of the aforementioned similarity for the sputtered and melt-spun materials, this modulus effect is likely to occur in the sputtered samples.

\section{Conclusion.}

As in some melt-spun alloys, a reversible structural ordering phenomenon corresponding to a partial equilibrium was clearly distinguished from a non-reversible evolution in a sputtered $\mathrm{Ni}_{24} \mathrm{Zr}_{76}$, by using both resistometric and elasticity measurements. Comparison of the results obtained using the two techniques supports the view that two, more or less independent types of order exist in the amorphous condition.

\section{Acknowledgments.}

The author wishes to thank J. Hillairet for his active support during this work. O. Bethoux is gratefully acknowledged for supplying the specimens used in this study.

\section{References}

[1] Chen, H. S., Proc. Int. Conf. on Rapidly Quenched Metals (Sendai) 1981, p. 495.

[2] Leake, J. A., Gibbs, M. R. J. and Evetrs, J. E., Proc. Int. Conf. on Rapidly Quenched Metals (Sendai) 1981, p. 9-513.

[3] Egami, T., Mater. Res. Bull. 13 (1978) 557.

[4] Scott, M. G. and Kursumovic, A., Acta Metall. 30 (1982) 853.

[5] Balanzat, E., Mairy, C. and Hillairet, J., J. Physique Colloq. 41 (1980) C8-871. 
[6] Balanzat, E., Hillairet, J., J. Phys. F 12 (1982) 2907.

[7] Dong, Y. D., Gregan, G. and Scott, M. G., J. Non-Cryst. Solids 43 (1982) 403.

[8] Scott, M. G., Gregan, G. and Dong, Y. D., Proc. 4th Int. Conf. on Rapidly Quenched Metals (Sendai) 1981, p. 671.

[9] Buschow, K. H. J. and Beekmans, N. M., Phys. Rev. B 19 (1979) 3843.

[10] Babic, E., Ristic, R. and MiljaK, M., Solid State Commun. 39 (1981) 139.

[11] Anderson, A. C., Koch, C. C. and Scarbrough, J. O., Phys. Rev. B 26 (1982) 1156.

[12] RaveX, A., Lasjaunias, J. C. and Bethoux, O., Solid State Commun. 40 (1981) 853.

[13] Berry, B. S. in Metallic glasses (Am. Soc. Met. Ohio) 1978, Chap. 7.

[14] Perez, J., Cavaille, J. Y., Etienne, S. and Fouquet, F., J. Physique Colloq. 41 (1980) C8-850.

[15] Kursumovic, A., CahN, R. W. and Scott, M. G., Scri. Metall. 14 (1980) 1245.

[16] Srolovitz, D., Maeda, K., Vitek, V. and Egami, T., Philos. Mag. A 44 (1981) 847.

[17] Dederichs, P. H., LehmanN, C., Z. Phys. B 20 (1975) 155.

[18] Conen, J. B. and Fine, M. E. in "Metallic Solid Solutions " (W. A. Benjamin, Inc.) 1963, Chap. XXXII.

[19] Balanzat, E. and Hillairet, J., J. Phys. F 11 (1981) 1977.

[20] Balanzat, E., Halbwachs, M., Hillairet, J., Mairy, C., Guyot, P., Simon, J. P., Acta. Metall. 31 (1983) 883.

[21] Chamberod, A., Chambron, W. and Hillairet, J. in Les Amorphes Métalliques (Editions de Physique-Paris) 1983 , p. 329.

[22] Bethoux, O., private communication. 